\title{
Effect of papaya supplementation on oxidative stress markers in Parkinson's disease
}

\author{
Andrea Bolner ${ }^{1}$, Rocco Micciolo², Ottavio Bosello³, Giampietro Nordera ${ }^{1}$ \\ 10xidative Stress Center (CSOx), Casa di Cura Villa Margherita, Vicenza, Italy \\ 2Department of Psichology and Cognitive Sciences, University of Trento, Italy \\ ${ }^{3}$ Department of Medicine, University of Verona, Italy
}

\begin{abstract}
Objective: In Parkinson's disease (PD), oxidative processes occur that are probably involved in the progression of neuronal damage. Recent studies suggest that regular consumption of antioxidant-rich foods or supplementation with functional foods like fermented papaya, may reduce cellular oxidative stress and protect against many agerelated diseases by strengthening the physiological antioxidant barrier. Our study aims to assess the antioxidant properties of a commercial fermented papaya preparation (FPP) in PD by evaluation of its effects on a wide panel of oxidative stress markers in blood and urine.

Methods: A group of parkinsonian voluntary patients (T, $n=15)$ were treated 9 months with FPP and compared with a control group (NT, $n=12$ ). The efficacy of FPP in increasing the physiological antioxidant barrier was evaluated at the times 0, 6 and 9 months with the analysis of 23 oxidative markers including total radical oxygen species, homocysteine, biological antioxidant potential, glutathione, superoxide dismutase, uric acid, total bilirubin, iron, ferritin, coenzyme 010, 3-nitrotyrosine, total lipoperoxide, 4-hydroxy-nonenal, 8-hydroxydeoxyguanosine (8$\mathrm{OHdG}$ ) and 2-deoxyguanosine (2-dG).

Results: Among the considered markers, twenty not showed significant differences at times 0, 6 and 9 months between T and NT patients, demonstrating a consequent non-significant effect of FPP supplementation. Instead, three urinary markers of oxidative stress on nucleic acids, 8-OHdG/2-dG, 2-dG/uric acid and 2-dG/creatinine showed statistical significant interactions between 'time' and 'treatment', highlighting an effective better response to oxidative attack for T than NT.
\end{abstract}

Conclusions: Papaya supplementation for a medium-long time seems able to affect positively the turnover of oxidized nucleic acids helping to restore the normal nitrogenous bases into nucleotide chains and to replace those altered by radicals' attack.
Received: March 17, 2016 Accepted: April 19, 2016 Published: September 6, 2016

Address for correspondence: Andrea Bolner, Laboratorio Analisi Casa di Cura Villa Margherita, Via Costacolonna, 6 36057 Arcugnano, Vicenza, Italy. bolner.andrea@gmail.com

Key Words: Oxidative stress markers, papaya, Parkinson's disease

\section{INTRODUCTION}

The cause of cell death in neurodegenerative diseases remains unknown but the formation of free radicals and the occurrence of oxidative stress may be a common component of many such disorders. In parkinsonian's substantia nigra many key alterations occur, in iron handling, mitochondrial function and antioxidant defenses that can result in oxidative stress. The free radical overproduction mediates a wide pattern of oxidative damages on cellular lipids, proteins and DNA bases [1-16] that do not appear related to levodopa administration [17].

Oxidative damages in basal ganglia are found even in other degenerative disorders such multiple system atrophy, progressive supranuclear palsy and Huntington's disease [18-20]. Moreover, studies on biochemical changes occurring in Alzheimer's disease (AD), motor neuron disease and diabetic neuropathy also suggest the involvement of free radicals in neurodegeneration process [21-24]. It is suggestive to think that, irrespective of the primary cause of individual neurodegenerative disorder, the onset of oxidative stress may be a common mechanism by which neuronal death occurs and contributes to disease progression. Recent studies suggest that regular consumption of antioxidant-rich foods may reduce cellular oxidative stress and protect against age-related diseases by strengthening the physiological antioxidant barrier. Our study aims to assess the antioxidant and neuroprotection properties of a fermented papaya preparation (FPP) in Parkinson's disease (PD) patients. FPP is a supplement food, rich in amino acids and carbohydrates product from yeast fermentation of Carica papaya.

The nutritional properties of papaya fruit and the composition of FPP were carefully investigated and described [25-26] but the mechanisms of its antioxidant capacity restoring was not fully understood. Probably, FPP acts both as a direct antioxidant (thanks to its molecular asset) and as an indirect gene up-regulator of enzymes such catalase, glutathione peroxidase and superoxide dismutase and other molecules involved in the strengthening of the antioxidant barrier and repair mechanisms of oxidative damages [27-28]. Many reports on chronic and degenerative diseases such thalassemia, cirrhosis, diabetes, aging and on performance sports showed that FPP favorably modulates immunological, hematological, inflammatory, vascular and oxidative stress damage parameters [29-43]. For these direct and indirect positive effects on health, FPP was therefore proposed as a 'functional food' [44].

With our study, we wanted to verify if FPP can acts as free radical scavenger even in PD and so provide neuroprotection. This observational study, conducted on a group of PD voluntary patients treated long term with 
FPP, has evaluated the efficacy of this food in modifying the blood and urine levels of a wide panel of oxidative stress markers [15] and in increasing the physiological antioxidant barrier.

\section{SUBJECTS AND METHODS}

The research was conducted according to the principles of the Declaration of Helsinki.

\section{Patients}

Serum, plasma and urine samples were obtained from 27 voluntary patients with PD (mean age 64.3 \pm 9.1 years), all in stages 1-3 of Hoehn Yahr scale, treated with similar levodopa therapies remained unchanged in course of the study. The patients will be then randomly divided into 2 groups: the first group (15 subjects, 8 males and 7 females) was treated (T) for 9 months, in addition to levodopa, with $9 \mathrm{~g}$ /day of a commercial certified papaya preparation administered by mouth as previously reported $[26,34,45]$, while the second group (12 subjects, 6 males and 6 females) received levodopa therapy only (NT).

\section{Biological samples}

The biological samples were collected from all patients at the times 0, 6 and 9 months. Blood was collected in vacuum sealed tubes without anticoagulant, with EDTA or sodium citrate depending on the analytical method. After sampling, the tubes were immediately centrifuged at $3500 \mathrm{rpm}$ for $10 \mathrm{~min}$ at $4^{\circ} \mathrm{C}$ and the plasma or serum samples frozen at $-80^{\circ} \mathrm{C}$ until analysis. First morning spot urine samples were also collected and frozen at $-80^{\circ} \mathrm{C}$.

\section{Oxidative stress markers analysis}

Plasma homocysteine (Hcy), 4-hydroxynonenal (4HNE), total and reduced blood glutathion (GSH-tot and GSH-red) were analysed by HPLC and fluorimetric detection using diagnostic kits purchased from Eureka Lab Division (Chiaravalle, Italy); similarly, determinations of plasmatic coenzyme Q10 and 3-nitrotyrosine (3-NT) were performed using Eureka HPLC kits with UV detection.

Superoxide dismutase (SOD) was determined in red blood cells with an automatized colorimetric kit (Ransod, Randox) and the enzymatic activity was expressed as function of hemoglobin concentration (Units/g Hb).

Analysis of urinary 8-hydroxydeoxyguanosine (8-OHdG) and 2-deoxyguanosine (2-dG) were performed with a previously reported HPLC method with electrochemical detection [9]: the values of $8-\mathrm{OHdG}$ and 2-dG were expressed either as reciprocal ratio $(8-\mathrm{OHdG} / 2 \mathrm{dG}$ ) and as function of the urinary creatinine (8-OHdG/ cr and 2-dG/cr) and uric acid (8-OHdG/ua and 2-dG/ ua). The oxidizing capacity of the plasma, understood as total content of oxygen free radicals (ROS), the biological antioxidant potential (BAP), understood as total content of antioxidant species and the total lipoperoxides content were determined in serum with the colorimetric assays d-ROMs (derivatives of Reactive Oxygen Metabolites), BAP and LP CHOLOX (level of lipoperoxides in circulation, resulting mainly from cholesterol) test purchased from Diacron (Grosseto, Italy).

The REDOX balance was determined by an experimental algorithm that relates the values of the d-ROMs and BAP between them and with their respective cut-off (BAP/ BAP cut-off divided by d-ROMS cut-off/d-ROMs).

Hemoglobin $(\mathrm{Hb})$ was analysed in whole blood by a hematology analyzer (BC5380, Mindray) and serum ferritin (FER) by a fluoroimmunoassay (Vidas, Biomerieux). Serum iron (Fe), uric acid (UA), total bilirubin (BT), urinary uric acid (U-UA) and creatinine (U-CR) were determined with a clinical chemistry multiparametric analyzer (BT-3500, Biotecnica); the urinary concentration of uric acid was expressed as function of the creatinine value (U-UA/cr).

\section{Statistical analysis}

Data were analyzed by means of a two-factor repeated measure ANOVA, with one factor between subjects (treatment group, at 2 levels) and one factor within subjects (time factor, at 3 levels). To account for the lack of the 'sphericity' assumption [46], the Box correction [47] was applied at the F test for the main effect of time and at the $\mathrm{F}$ test for the interaction between time and treatment group. All the analyses were performed employing R 3.1.1 software [48]; a significance level of $5 \%$ was always adopted $(\mathrm{P}<0.05)$.

\section{RESULTS}

Since most of the analytes studied (Hcy, GSH-tot, GSH-red, Q10, 8-OHdG/cr, 2-dG/cr, 8-OHdG/ua, 2-dG/ ua, 8-OHdG/2dG, 3-NT, 4-HNE, SOD, BAP, REDOX balance, BT, FER) showed a very skewed distribution, the corresponding log-transformed values were analyzed (the base 10 was adopted). The remaining variables d-ROMs, CHOLOX, Hb, Fe, UA, U-UA/cr, instead, remained untransformed. Table 1 shows summary statistics (mean, standard deviation and median for original values) for the 27 subjects, separately for NT and T groups. A two-factor repeated measure ANOVA was performed as described in the methods and the results are reported in Table 2.

There were 9 variables (Hcy, GSH-red, GSH-red/tot, Q10, 4-HNE, REDOX balance, UA, Fe, BT) for which none of the three $\mathrm{F}$ tests yielded a significant result. Therefore, for these variables, neither a group difference nor a time difference was found. On the other hand, there were 11 variables (GSH-tot, 8-OHdG/cr, 8-OHdG/ ua, 3-NT, SOD, BAP, d-ROMs, CHOLOX, Hb, FER, $\mathrm{U}-\mathrm{UA} / \mathrm{cr}$ ) for which only the time effect was significant. Therefore, the mean levels of these variables changed along with time, but in a similar manner in $\mathrm{T}$ and NT subjects.

In particular, these variables did not show significant differences between two groups and, therefore, it is likely 
Table 1. Descriptive statistics for not treated (NT) and for FPP treated subjects (T) at time 0 (basal), 6 and 9 months. The table shows, according to the biological sample, mean $(\mathbf{m})$, standard deviations $(\mathbf{s d})$ and median $(\mathbf{m e d})$ values for each oxidative stress marker; between the brackets are reported the units of measure.

\begin{tabular}{|c|c|c|c|c|c|c|c|c|c|c|c|c|c|c|c|c|c|c|}
\hline & \multicolumn{6}{|c|}{ Basal } & \multicolumn{6}{|c|}{ After 6 months } & \multicolumn{6}{|c|}{ After 9 months } \\
\hline & \multicolumn{3}{|c|}{ NT } & \multicolumn{3}{|c|}{$T$} & \multicolumn{3}{|c|}{ NT } & \multicolumn{3}{|c|}{$T$} & \multicolumn{3}{|c|}{ NT } & \multicolumn{3}{|c|}{$\mathrm{T}$} \\
\hline & $\mathrm{m}$ & sd & med & m & sd & med & m & sd & med & $\mathrm{m}$ & sd & ed & $\mathrm{m}$ & sd & med & $\mathrm{m}$ & sd & med \\
\hline \multicolumn{19}{|l|}{ Plasma markers } \\
\hline Hcy $(\mu \mathrm{mol} / \mathrm{l})$ & 15.1 & 5.8 & 13.1 & 14.2 & 5.5 & 15.0 & 11.7 & 4.2 & 11.8 & 15.4 & 8.3 & 14.7 & 15.2 & 6.5 & 14.4 & 15.3 & 5.2 & 15.8 \\
\hline Q10 ( $\mu \mathrm{g} / \mathrm{l})$ & 866 & 725 & 716 & 734 & 626 & 496 & 491 & 365 & 457 & 627 & 707 & 402 & 504 & 404 & 423 & 19 & 609 & 316 \\
\hline 3-NT ( $\mu \mathrm{g} / \mathrm{l})$ & 159 & 67 & 156 & 128 & 61 & 124 & 96 & 41 & 97 & 118 & 39 & 111 & 134 & 34 & 122 & 134 & 43 & 136 \\
\hline 4-HNE (nmol/l) & 41.6 & 19.9 & 40.1 & 33 & 10.9 & 33 & 32 & 14 & 32.3 & 42.1 & 16.7 & 41.5 & 42.8 & 16.5 & 44.9 & 34.5 & 13.5 & 38.9 \\
\hline \multicolumn{19}{|l|}{ Blood markers } \\
\hline GSH-tot ( $\mu \mathrm{mol} / \mathrm{l})$ & 1640 & 239 & 1622 & 1748 & 199 & 1769 & 1586 & 197 & 1554 & 1447 & 177 & 1450 & 1661 & 246 & 1585 & 1521 & 189 & 1457 \\
\hline GSH-red ( $\mu \mathrm{mol} / \mathrm{l})$ & 943 & 199 & 846 & 1042 & 246 & 997 & 863 & 169 & 824 & 901 & 210 & 824 & 955 & 177 & 968 & 880 & 112 & 888 \\
\hline GSH-r & 62.9 & 12.5 & 60.7 & 59.7 & 13.1 & 55.4 & 60.5 & 10.4 & 59.3 & 64.6 & 14.8 & 58.6 & 60.3 & 7.7 & 58.4 & 59.9 & 3.2 & 57 \\
\hline $\operatorname{SOD}(\mathrm{U} / \mathrm{g} \mathrm{Hb})$ & 1856 & 438 & 1839 & 1826 & 430 & 1709 & 1519 & 400 & 1469 & 1510 & 312 & 1525 & 1624 & 308 & 1548 & 1662 & 245 & 1671 \\
\hline $\mathrm{Hb}$ (g/dl) & 135 & 0.9 & 13.5 & 13.9 & 1.3 & 13.4 & 13.9 & 1.1 & 14.0 & 14.2 & 1.0 & 14.1 & 14.2 & 0.8 & 14.2 & 14.2 & 1.3 & 14 \\
\hline \multicolumn{19}{|l|}{ Urine markers } \\
\hline 8-OHdG/cr $(\mu \mathrm{g} / \mathrm{g})$ & 242 & 576 & 66 & 74.1 & 68.6 & 68.1 & 52 & 76 & 24 & 29.7 & 35.7 & 17.2 & 31 & 31 & 25 & 22.5 & 26.8 & 10.4 \\
\hline 2-dG/cr $(\mu \mathrm{g} / \mathrm{g})$ & 6316 & 9843 & 2615 & 7586 & 21408 & 1426 & 820 & 1129 & 594 & 2742 & 6002 & 162 & 131 & 242 & 58 & 1258 & 2236 & 397 \\
\hline 8-OHdG/2-dG (ng/ug) & 51.2 & 70.5 & 21.7 & 150 & 237 & 55 & 183.3 & 259.4 & 31.9 & 231 & 332 & 58 & 868 & 1817 & 175 & 133 & 230 & 53 \\
\hline $8-\mathrm{OHdG} / \mathrm{ua}(\mu \mathrm{g} / \mathrm{g})$ & 931 & 1319 & 411 & 1098 & 1256 & 726 & 118 & 113 & 91 & 127 & 169 & 72 & 113 & 110 & 92 & 73 & 75 & 38 \\
\hline 2-dG/ua ( $\mu g / g)$ & 157010 & 320001 & 34408 & 36147 & 61957 & 10421 & 3871 & 6096 & 1773 & 8948 & 18994 & 583 & 774 & 1874 & 225 & 3977 & 5538 & 803 \\
\hline U-UA/cr (mg/g) & 191 & 133 & 222 & 167 & 160 & 94 & 325 & 92 & 335 & 293 & 110 & 297 & 281 & 140 & 283 & 310 & 126 & 318 \\
\hline \multicolumn{19}{|l|}{ Serum markers } \\
\hline $\mathrm{BAP}(\mu \mathrm{Eq} / \mathrm{l})$ & 1968 & 348 & 2096 & 2052 & 227 & 2048 & 1862 & 189 & 1793 & 1836 & 202 & 1801 & 1892 & 377 & 1760 & 1771 & 184 & 1778 \\
\hline d-ROMs (U carr) & 356 & 45 & 374 & 365 & 63 & 369 & 326 & 54 & 321 & 332 & 46 & 341 & 331 & 62 & 345 & 346 & 65 & 323 \\
\hline CHOLOX ( $\mu \mathrm{Eq} / \mathrm{l})$ & 398 & 95 & 393 & 472 & 124 & 461 & 526 & 123 & 519 & 554 & 119 & 555 & 397 & 224 & 329 & 452 & 220 & 509 \\
\hline REDOX balance & 0.76 & 0.14 & 0.77 & 0.79 & 0.14 & 0.77 & 0.8 & 0.12 & 0.78 & 0.77 & 0.12 & 0.74 & 0.79 & 0.14 & 0.79 & 0.72 & 0.17 & 0.69 \\
\hline UA (mg/dl) & 4.46 & 1.33 & 4.05 & 4.2 & 1.9 & 3.9 & 4.62 & 1.55 & 4.25 & 3.88 & 1.51 & 3.9 & 4.69 & 1.25 & 4.65 & 4.19 & 1.66 & 4.5 \\
\hline $\mathrm{Fe}(\mu \mathrm{g} / \mathrm{dl})$ & 88.3 & 23.3 & 87.5 & 87.6 & 21 & 86 & 90.4 & 30.3 & 100.5 & 94.1 & 19.5 & 86 & 111.2 & 34.8 & 118.5 & 88.7 & 32 & 79 \\
\hline BT (mg/dl) & 0.79 & 0.26 & 0.75 & 0.77 & 0.41 & 0.68 & 0.72 & 0.29 & 0.62 & 0.74 & 0.24 & 0.72 & 0.82 & 0.37 & 0.65 & 0.79 & 0.33 & 0.74 \\
\hline FER $(\mu \mathrm{g} / \mathrm{l})$ & 174 & 127 & 130 & 155 & 130 & 138 & 174 & 143 & 122 & 171 & 139 & 141 & 164 & 147 & 105 & 135 & 113 & 117 \\
\hline
\end{tabular}

that variations in time respect to the basal value could be linked to the progression of the disease, which represents the common condition of both groups. A somewhat regular decrease over time was observed for $8-\mathrm{OHdG} /$ cr, 8-OHdG/ua and BAP, while an opposite pattern was observed for Hb. For GSH-tot, SOD and d-ROMs, average values at 6 and 9 months were lower than those at time 0 , while an opposite pattern was observed for $\mathrm{U}-\mathrm{UA} / \mathrm{cr}$. Mean values of 3-NT were reduced after 6 months, but after 9 months a return to the basal value was found. Similarly, average CHOLOX values increased between 0 and 6 months, but they returned to the basal value after 9 months.

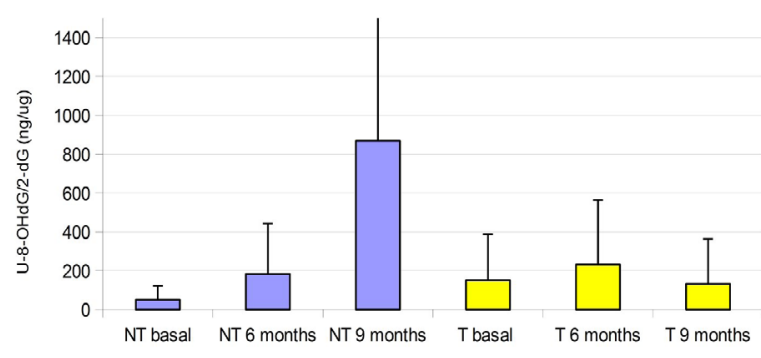

Figure 1. Mean values of 8-OHdG/2-dG ratio in urine in treated $(\mathrm{T})$ and not treated (NT) subjects at basal time, after 6 and 9 months.
Finally, for the remaining 3 variables $(8-O H d G / 2-d G$, 2-dG/ua and 2-dG/cr), a significant interaction effect was found. Therefore, for these variables some modifications of the mean values among the three considered times were found, and these changes were significantly different between T and NT subjects.

The mean values of 8 -OHdG/2-dG, increase progressively in the three times in NT group only, while these remain substantially constant in $\mathrm{T}$. This trend was just perceptible in the analysis for the first two times, but it becomes significant when considering all the three times (Figure 1).

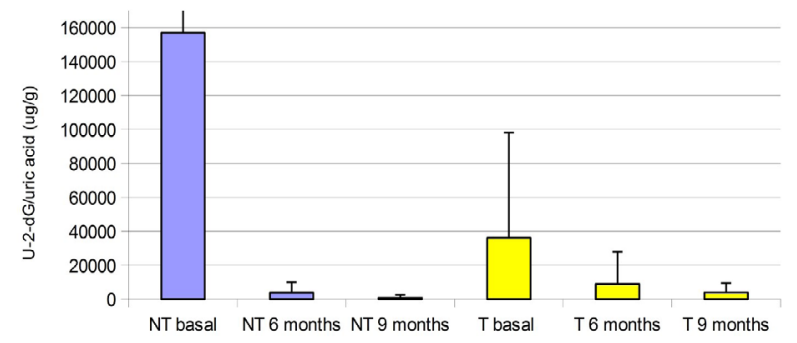

Figure 2. Mean values of the 2-dG/uric acid ratio in urine in treated (T) and not treated (NT) subjects at basal time, after 6 and 9 months. 
Table 2. Results of the two-factor repeated measure ANOVA. The results of the F tests for the main effects of time and treatment group, as well as for the interaction are reported. The P values for the time effect and for the interaction are calculated employing the Box correction. Significant interactions are displayed in bold italic and significant main effect of time is displayed in bold.

\begin{tabular}{|c|c|c|c|c|c|c|}
\hline \multirow{2}{*}{ Marker } & \multicolumn{2}{|c|}{ Treatment group } & \multicolumn{2}{|c|}{ Time } & \multicolumn{2}{|c|}{ Interaction } \\
\hline & $\mathbf{F}$ & $\mathbf{P}$ & $\mathbf{F}$ & $\mathbf{P}$ & $\mathbf{F}$ & $\mathbf{P}$ \\
\hline 4-HNE & 0.11 & 0.743 & 0.04 & 0.843 & 2.73 & 0.112 \\
\hline GSH-red/tot & 0 & 0.965 & 0.29 & 0.598 & 0.59 & 0.449 \\
\hline REDOX balance & 0.37 & 0.551 & 0.74 & 0.397 & 1.5 & 0.232 \\
\hline UA & 0.75 & 0.395 & 0.82 & 0.373 & 1.12 & 0.301 \\
\hline BT & 0 & 0.981 & 1.14 & 0.297 & 0.98 & 0.333 \\
\hline $\mathrm{Fe}$ & 0.63 & 0.435 & 1.83 & 0.188 & 3.04 & 0.093 \\
\hline Hcy & 0.22 & 0.645 & 2.1 & 0.161 & 2.82 & 0.107 \\
\hline Q10 & 0 & 0.989 & 2.48 & 0.13 & 0.14 & 0.715 \\
\hline GSH-red & 0.22 & 0.647 & 2.62 & 0.119 & 1.25 & 0.276 \\
\hline 8-OHdG/2-dG & 0.5 & 0.486 & 3.20 & 0.086 & 5.69 & 0.025 \\
\hline $3-N T$ & 0 & 0.997 & 4.32 & 0.048 & 3.08 & 0.092 \\
\hline FER & 0.14 & 0.714 & 4.76 & 0.039 & 1.85 & 0.186 \\
\hline SOD & 0.01 & 0.915 & 5.03 & 0.034 & 0.08 & 0.782 \\
\hline d-ROMs & 0.26 & 0.616 & 5.34 & 0.03 & 0.10 & 0.755 \\
\hline CHOLOX & 1.32 & 0.262 & 5.47 & 0.028 & 0.17 & 0.682 \\
\hline GSH-tot & 1.3 & 0.267 & 5.69 & 0.027 & 2.62 & 0.121 \\
\hline BAP & 0.02 & 0.883 & 5.87 & 0.023 & 1.47 & 0.237 \\
\hline $\mathrm{Hb}$ & 0.39 & 0.541 & 6.9 & 0.015 & 0.88 & 0.357 \\
\hline U-UA/cr & 0.06 & 0.81 & 11.1 & 0.003 & 0.59 & 0.45 \\
\hline 2-dG/cr & 0.72 & 0.404 & 14.84 & 0.001 & 4.36 & 0.048 \\
\hline 8-OHdG/cr & 0.66 & 0.425 & 17.85 & $<0.001$ & 0.06 & 0.814 \\
\hline 2-dG/ua & 0.45 & 0.507 & 30.84 & $<0.001$ & 4.30 & 0.049 \\
\hline 8-OHdG/ua & 0.18 & 0.675 & 42.57 & $<0.001$ & 0.18 & 0.677 \\
\hline
\end{tabular}

In contrast, the mean values of the variable 2-dG/ ua gradually decrease in NT group in the three times while in $\mathrm{T}$, after an initial reduction between 0 and 6 months remain substantially constant (Figure 2). Note that, U-UA/cr ratios increases in the same way in time for both NT and T groups (Figure 3). Therefore, the observation that in the latter the ratio $2-\mathrm{dG} / \mathrm{ua}$ is not reduced further between 6 and 9 months, corroborates the demonstration that 2-dG increase over time in $\mathrm{T}$. To confirm this observation, a similar result is obtained for the ratio $2-\mathrm{dG} / \mathrm{cr}$. The mean value of $2-\mathrm{dG} / \mathrm{cr}$ decrease gradually in the three times in NT subjects, while in T group, after an initial reduction between 0 and 6 months, remain substantially constant between 6 and 9 months (Figure 4).

\section{DISCUSSION}

Oxidative stress contributes to the cascade leading to dopamine cell degeneration in PD. The alteration of the physiological redox balance in PD is intimately linked to other components of the degenerative process, such as mitochondrial dysfunction, excitotoxicity, nitric oxide toxicity and inflammation. It is therefore difficult to determine whether oxidative stress leads to, or is a consequence of, these events. Since previous

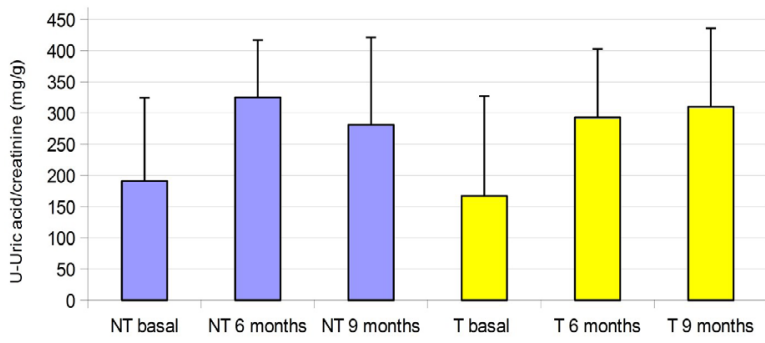

Figure 3. Mean values of the uric acid/creatinine ratio in urine in treated $(\mathrm{T})$ and not treated (NT) subjects at basal time, after 6 and 9 months.

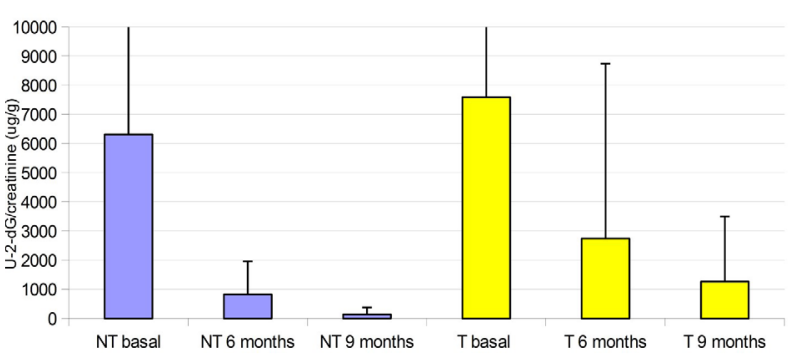

Figure 4. Mean values of the 2-dG/creatinine ratio in urine in treated (T) and not treated (NT) subjects at basal time, after 6 and 9 months. 
authors have described some potential benefits of FPP supplementations like anti-inflammatory, antioxidant, immune-stimulatory and mRNA transcription inductor of antioxidant enzymes, we wanted to evaluate the effects of a prolonged assumption of this functional and nutraceutical food in PD. These effects were evaluated by means of a large panel of oxidative stress markers whose variations during time have been studied in relationship with the FPP treatment.

They were part of the panel markers of oxidizing power (d-ROMs and Hcy), antioxidant barrier (BAP, GSH, SOD, UA, BT), mitochondrial function (Q10), peroxidation of proteins (3-NT), lipids (CHOLOX and 4-HNE), and nuclear acids (urinary 8-OHdG, its corresponding not hydroxylated nucleoside $2-\mathrm{dG}$, the reciprocal respective ratio $8-\mathrm{OHdG} / 2-\mathrm{dG}$ and their ratios versus creatinine and uric acid as previously reported) [12]. Furthermore, because of the several observations that in PD the iron levels are increased in brain, we have analyzed the plasma concentrations of Fe, FER and blood $\mathrm{Hb}$ to evaluate the iron metabolism.

The statistical data processing at the end of our study showed no evidence of significant treatment effects in many biomarkers and several time-trends effects probably attributable simply to the course of disease. Some analytes have not changed over time for either T or NT groups (Hcy, GSH-red, GSH-red/tot ratio, Q10, 4-HNE, REDOX balance, UA, Fe and BT). Statistically significant increases were instead observed for $\mathrm{Hb}$ and for $\mathrm{U}-\mathrm{UA} / \mathrm{cr}$, but not different for T and NT subjects. The increase of urinary uric acid, the end product of purine catabolism, was an expected change in neurodegeneration $[1,18]$. The slight increase in hemoglobin levels for both $\mathrm{T}$ and NT patients was quite surprising. Indeed, it has been previously suggested that anemia may be a risk factor for PD [49]. Even if the association between anemia experienced early in life and the later development of PD remain uncertain, it seems unlikely that in course of disease may be activated a physiological contrast process.

Even despite to previous observations [28] according to which we expected that the treatment with FPP would result in higher expression of the enzyme GSH peroxidase gene and in a consequent increase of GSHred and of GSH-red/tot ratio, in our data these markers not change significantly over time. Keeping in mind the contemporaneous decrease in both groups of GSH-tot, statistically significant and compatible with a progressive increase of the oxidative insult in PD, the substantial invariance of GSH-red and GSH-red/tot ratio can be interpreted as a physiological counter-regulatory response mechanism that acts independent from FPP treatment.

During the nine months of observation, in both $\mathrm{T}$ and NT groups, SOD and BAP decreased, as expected in the hypothesis of a gradually reduced efficacy of the enzymatic antioxidant response and persistent overproduction of free radials in this degenerative disease. It is however difficult to explain the slight decrease in both groups of the total ROS, not justified by contemporary upgrades of the antioxidant barrier.

To understand the decreased levels of urinary 8-OHdG ratios $v$ s creatinine and uric acid in both $\mathrm{T}$ and $\mathrm{NT}$ patients it is necessary to remember, that in neurodegenerative diseases, nuclear and mitochondrial DNA are probably the most biologically relevant target of oxidative attack. Although more than 20 different oxidative modifications of DNA bases have been identified, the major product of DNA impairment is 8-hydroxyguanine (8-OHGua) and its nucleoside 8 -OHdG. As a consequence of the repair systems of DNA in vivo, the resulting 8-OHdG is excreted without further metabolism from cells and blood into urine. Thus, the urinary excretion of 8-OHdG may reflect the extent of oxidative DNA damage. Since measures of urinary levels of 8 -OHdG mark the total oxidative damage of DNA, a reduction in its excretion rate may be interpreted as a positive event. Nevertheless, this reduction could result not only from a decreased oxidation of DNA bases (likely to be beneficial) but even from a diminished cellular turnover and DNA repair (likely to be detrimental), phenomenon already described in elderly patients with neurodegenerative pathologies.

To overcome the individual efficiency of reparing systems, some authors $[50,51]$ have previously proposed the expression of $8-\mathrm{OHdG}$ as function of the corresponding not hydroxylated free base 2-dG [12, 15]. In order to obtain more biochemical information, we wanted to express 8-OHdG, not only vs 2-dG but also $v s$ creatinine and uric acid in the purpose to take into account either the concentration of the urinary samples either the excretion of uric acid, the end result of purine nucleobases catabolism.

Despite to the persistence of oxidative damage on DNA caused by the disease, the observed decreases of 8-OHdG ratios during 9 months either in T and NT patients could show a tendency to a gradual slowdown of DNA turnover in both groups not counteracted by supplementation with FPP. On the contrary, the statistical analysis show that while in the NT patients 2-dG ratios continue to decline and 8-OHdG/2-dG to increase, in T subjects the increase of $2-\mathrm{dG}$ both $v s$ creatinine or uric acid undergoes a stabilization of the $8-\mathrm{OHdG} / 2$-dG ratio compared to the baseline value. These significant trends in the two groups of patients are probably explained by the occurrence of two opposite phenomena in T and NT groups related to the FPP treatment.

Indeed, it is possible to hypothesize, that supplementation with FPP, through unclear molecular mechanisms, can strengthen the DNA turnover (understood as the sum of pathways of anabolism, catabolism and anabolic recovery of deoxynucleosides, called 'salvage') otherwise slowed because of the disease. As the treatment increase 2-dG levels and therefore the bioavailability of native nucleosides, FPP seems allow a counter-regulatory response of replacement of the altered nitrogenous base (8-OHdG) with native base $(2-d G)$ through an enhancement of the metabolic pathway of nucleoside salvage.

In conclusion, the oxidative phenomenon in neurodegeneration has been widely documented and is therefore interesting to explore treatments that can prevent or slow its progression. FPP is proposed as a functional food that can modulate the physiological antioxidant response. Our work has shown that FPP 
supplementation for medium-long time is able to positively affect the turnover of nucleic acids helping to restore the normal nitrogenous bases into nucleotide chains and to replace those altered by radicals attack. Further studies are however needed to understand if the efficacy of this supplementation can be demonstrated even in other cellular compartments or might results in the enhancement of other metabolic pathways with antioxidant effect.

\section{REFERENCES}

1. Sanyal J, Bandyopadhyay SK, Banerjee TK, Mukherjee SC, Chakraborty DP, Ray BC, Rao VR. Plasma levels of lipid peroxides in patients with Parsinson's disease. Eur Rev Med Pharmacol Sci 2009; 13:129-32.

2. Chen CM, Liu JL, Wu YR, Chen YC, Cheng HS, Cheng ML, Chiu DT. Increased oxidative damage in peripheral blood correlates with severity of Parkinson's disease. Neurobiol Dis 2009; 33:429-35.

3. Shukla R, Rajani M, Srivastava N, Barthwal MK, Dikshit M. Nitrite and malondialdehyde content in cerebrospinal fluid of patients with Parkinson's disease. Int J Neurosci 2006; 116:1391-402.

4. Baillet A, Chanteperdrix V, Trocme C, Casez P, Garrel C, Besson $\mathrm{G}$. The role of oxidative stress in amyotrophic lateral sclerosis and Parkinson's disease. Neurochem Res 2010; 35:1530-7.

5. Elokda A, Di Francisco-Donoghue J, Lamberg EM, Werner WG. Effects of exercise induced oxidative stress on glutathione levels in Parkinson's disease on and off medication. J Neurol 2010; 257:1648-53.

6. Martin HL, Teismann P. Glutathione: a review on its role and significance in Parkinson's disease. FASEB J 2009; 23:3263-72.

7. Lee M, Tazzari V, Giustarini D, Rossi R, Sparatore A, Del Soldato P, McGeer E, McGeer PL. Effects of hydrogen sulfide-releasing L-DOPA derivatives on glial activation: potential for treating Parkinson disease. J Biol Chem 2010; 285:17318-28.

8. Grammas P, Martinez J, Miller B. Cerebral microvascular endothelium and the pathogenesis of neurodegenerative diseases. Expert Rev Mol Med 2011; 13:e19.

9. Larsen TR, Soderling AS, Caidahl K, Roepstorff P, Gramsbergen JB. Nitration of soluble proteins in organotypic culture models of Parkinson's disease. Neurochem Int 2008; 52:487-94.

10. Trostchansky A, Rubbo H. Lipid nitration and formation of lipidprotein adducts: biological insights. Amino Acids 2007; 32:517-22.

11. Hirayama M, Nakamura T, Watanabe H, Uchida K, Hama T, Hara T, Niimi Y, Ito M, Sobue G. Urinary 8-hydroxydeoxyguanosine correlate with hallucinations rather than motor symptoms in Parkinson's disease. Parkinsonism Relat Disord 2011; 17:46-9.

12. Bolner A, Pilleri M, De Riva V, Nordera GP. Plasmatic and urinary HPLC-ED determination of the ratio 8-OHdG/2-dG in Parkinson's disease. Clinical Lab 2011; 57:859-66.

13. Orsucci D, Mancuso M, Ienco EC, LoGerfo A, Siciliano G. Targeting mitochondrial dysfunction and neurodegeneration by means of coenzyme Q10 and its analogues. Curr Med Chem 201 1; 18:4053-64.

14. Calabrese V, Lodi R, Tonon C, D’Agata V, Sapienza M, Scapagnin G, Mangiameli A, Pennisi G, Stella AM, Butterfield DA. Oxidative stress, mitochondrial dysfunction and cellular stress response in Friedreich's ataxia. J Neurol Sci 2005; 233: 145-62.

15. Bolner A, Micciolo R, Bosello O, Nordera GP. A Panel of oxidative stress markers in Parkinson's disease. Clin Lab 2016; 62:105-12.

16. Jodko K, Litwinienko G. Oxidative stress in the neurodegenerative diseases: potential antioxidant activity of catecholamines. Postepy Biochem 2010; 56(3):248-59.

17. Oli G, Fazeli G, Kuhn W, Walitza S, Gerlach M, Stopper H. No increased chromosomal damage in L-DOPA-treated patients with Parkinson's disease: a pilot study. J Neural Transm; 117:737-46.

18. Cao B, Wei OO, Ou R, Yang J, Shang HF. Association of serum uric acid level with cognitive function among patients with multiple system atrophy. J Neurol Sci 2015; 359:363-6.

19. Martinez A, Dalfo E, Muntane G, Ferrer I. Glycolitic enzymes are targets of oxidation in aged human frontal cortex and oxidative damage of these proteins is increased in progressive supranuclear palsy. J Neural Transm 2008; 115:59-66.

20. Pena-Sanchez M, Riveron-Forment G, Zaldivar-Vaillant T, Soto-Lavastida A, Borrero-Sanchez J, Lara-Fernandez G, EstebanHernandez EM, Hernandez-Diaz Z, Gonzalez-Quevedo A, Fernandez-Almirall I, Perez-Lopez C, Castillo-Casanas Y, MartinezBonne O, Cabrera-Rivero A, Valdes-Ramos L, Guerra-Badia R, Fernandez-Carriera R, Menendez-Sainz MC, Gonzalez-Garcia S. Association of status redox with demographic, clinical and imaging parameters in patients with Huntington's disease. Clin Biochem 2015; 48:1258-63.

21. Greilberger J, Fuchs D, Leblhuber F, Greilberger M, Wintersteiger R, Tafeit E. Carbonyl proteins as a clinical marker in Alzheimer's disease and its relation to tryptophan degradation and immune activation. Clin Lab 2010; 56:441-8.

22. Hatanaka H, Hanyu H, Fukasawa R, Hirao K, Shimizu S, Kanetaka H, Iwamoto T. Differences in peripheral oxidative stress markers in Alzheimer's disease, vascular dementia and mixed dementia patients. Geriatr Gerontol Int 2015; 15(Suppl1):53-8. 
23. Lindblom R, Higgins G, Coughlan M, de Haan JB. Targeting mitochondria and reactive oxygen species-driven pathogenesis in diabetic nephropathy. Rev Diabet Stud 2015; 12:134-56.

24. Manna P, Jain SK. Obesity, oxidative stress, adipose tissue dysfunction, and the associated health risks: causes and therapeutic strategies. Metab Syndr Relat Disord 2015; 13:423-44.

25. Mahattantawee K, Manthey JA, Luzio G, Talcott ST, Gooder K, Baldwin EA. Total antioxidant activity and fiber content of select florida-grown tropical fruits. J Agric Food Chem 2006; 54:7355-63.

26. Aruoma OI, Hayashi Y, Marotta F, Mantello P, Rachmiliewitz E, Montagnier L. Applications and bioefficacy of the functional food supplement fermented papaya preparation. Toxicology 2010; 278:6-16.

27. Zhang J, Mori A, Chen Q, Zhao B. Fermented papaya preparations attenuates beta-amyloid precursor protein: beta-amyloid-mediated copper neurotoxicity in beta-amyloid precursor protein and betaamyloid precursor protein in Swedish mutation over-expressing SH-SY5Y cells. Neuroscience 2006; 143:63-72.

28. Marotta F, Koike K, Lorenzetti A, Jain S, Signorelli P, Metugriachuk Y, Mantello P, Locorotondo N. Regulating redox balance gene expression in healthy individuals by nutraceuticals: a pilot study. Rejuvenation Res 2010: 13:175-8.

29. Imao K, Wang H, Komatsu M, Hiramatsu M. Free radical scavenging activity of fermented papaya preparation and its effect on lipid peroxide level and superoxide dismutase activity in iron-induced epileptic foci of rats. Biochem Mol Biol Int 1998; 45:11-23.

30. Rimbach G, Guo Q, Akiyama T, Matsugo S, Moini H, Virgili F, Packer L. Ferric nitrilotriacetate induced DNA and protein damage: inhibitory effect of a fermented papaya preparation. Anticancer Res 2000: 20:2907-14

31. Rimbach G, Park YC, Guo Q, Moini H, Qureshi N, Saliou C, Takayama K, Virgili F, Packer L. Nitric oxide synthesis and TNF-alpha secretion in RAW 264.7 macrophages: mode of action of a fermented papaya preparation. Life Sci 2000; 67:679-94.

32. Marotta F, Barreto R, Tajiri H, Bertuccelli J, Safran P, Yoshida C, Fesce $\mathrm{E}$. The aging/precancerous gastric mucosa: a pilot nutraceutical trial. Ann NY Acad Sci 2004; 1019:195-9.

33. Marotta F, Pavasuthipaisit K, Yoshida C, Albergati F, Marandola P. Relationship between aging and susceptibility of erythrocytes to oxidative damage: in view of nutraceutical interventions. Rejuvenation Res 2006: 9:227-30.

34. Marotta F, Weksler M, Naito Y, Yoshida C, Yoshioka M, Marandola P. Nutraceutical supplementation: effect of a fermented papaya preparation on redox status and DNA damage in healthy elderly individuals and relationship with GSTMl genotype: a randomized, placebo-controlled, cross-over study. Ann NY Acad Sci 2006; 1067:400-7.

35. Aruoma OI, Colognato R, Fontana I, Gartlon J, Migliore L, Koike K, Coecke S, Lamy E, Mersch-Sundermann V, Laurenza I, Benzi L, Yoshino F, Kobayashi K, Lee MC. Molecular effects of fermented papaya preparation on oxidative damage, MAP kinase activation and modulation of the benzo(a)pyrene mediated genotoxicity. Biofactors 2006; 26:147-59

36. Danese C, Esposito D, D’Alfonso V, Cirene M, Ambrosino M, Colotto M. Plasma glucose level decreases as collateral effect of fermented papaya preparation use. Clin Ter 2006; 157:195-8.
Bolner et al: Papaya and oxi-stress markers in Parkinson

37. Marotta F, Yoshida C, Barreto R, Naito Y, Packer L. Oxidativeinflammatory damage in cirrhosis: effect of vitamin $\mathrm{E}$ and a fermented papaya preparation. J Gastroenterol Hepatol 2007; 22:697-703.

38. Marotta F, Koike K, Lorenzetti A, Naito Y, Fayet F, Shimizu H, Marandola P. Nutraceutical strategy in aging: targeting heat shock protein and inflammatory profile through understanding interleukin-6 polymorphism. Ann NY Acad Sci 2007; 1119:196-202.

39. Amer J,Goldfarb A, Rachmilewitz EA, Fibach E. Fermented papaya preparation as redox regulator in blood cells of beta-thalassemic mice and patients. Phytother Res 2008; 22 820-8.

40. Noda Y, Murakami S, Mankura M, Mori A. Inhibitory effect of fermented papaya preparation on hydroxyl radical generation from methylguanidine. J Clin Biochem Nutr 2008; 43:185-90.

4l. Ghoti H, Rosenbaum H, Fibach E, Rachmilewitz EA. Decreased hemolysis following administration of antioxidant-fermented papaya preparation (FPP) to a patient with PNH. Ann Hematol 2010; 89:429-30.

42. Collard E, Roy S. Improved function of diabetic wound-site macrophages and accelerated wound closure in response to oral supplementation of a fermented papaya preparation. Antioxid Redox Signal 2010; 13:599-606.

43. Fibach E, Tan ES, Jamuar S, Ng I, Amer J, Rachmilewitz EA Amelioration of oxidative stress in red blood cells from patients with beta-thalassemia major and intermedia and E-beta-thalassemia following administration of a fermented papaya preparation. Phytother Res 2010; 24:1334-8.

44. Marotta F, Celep GS, Cabeca A, Polimeni A. Novel concepts on functional foods and nutrigenomics in healthy aging and chronic diseases: a review of fermented papaya preparation research progress. Funct Foods Health Dis 2012; 2:120-36.

45. Scuccato R, Pilleri M, Nordera G. Effect of fermented papaya preparation on patients affected by Parkinson's disease. Basal Ganglia 2011; 1:154 (Congress Abstract: XXXVIII National Congress of the Italian Society for the Study of Parkinson Disease, Extrapyramidal Diseases and Dementia (LIMPE) Venezia Lido, Italy, October 5-8, 2011).

46. Agresti A, Finlay B. Statistical Methods for the Social Sciences. 4th edition, Pearson Prentice Hall, New Jersey 2009:393.

47. Box G. Some theorems on quadratic forms applied in the study of analysis of variance problems: effect of inequality of variance in the one-way classification. Ann Math Statist 1954; 25:290-302.

48. R Core Team. A language and environment for statistical computing. R Foundation for Statistical Computing, Vienna, 2014.

49. Savica R, Grossardt BR, Carlin JM, Icen M, Bower JH, Ahlskog JE, Maraganore DM, Steensma DP, Rocca WA. Anemia or low hemoglobin levels preceding Parkinson disease: a case-control study. Neurology 2009; 73:1381-7.

50. Wilson VL, Taffe BG, Shields PG, Povey AC, Harris CC. Detection and quantification of 8-hydroxydeoxyguanosine adducts in peripheral blood of people exposed to ionizing radiation. Environ Health Perspect 1993; 99:261-3.

51. Yen MY, Kao SH, Wang AG, Wei YH. Increased 8-hydroxy-2'deoxyguanosine in leukocyte DNA in Leber's hereditary optic neuropathy. Invest Ophthalmol Vis Sci 2004; 45(6):1688-91. 